\title{
Safer Roads: Comparisons Between Road Assessment Program and Composite Road Safety Index Method
}

\author{
Intan Suhana Mohd Razelan ${ }^{1, *}$ \\ ${ }^{1}$ Universiti Malaysia Pahang, 26600, Pekan, Pahang
}

\begin{abstract}
In most countries, crash statistics have becoming very crucial in evaluating road's safety level. In Malaysia, these data are very important in deciding crash-prone areas known as black spot where specific road improvements plan will be proposed. However due to the unavailability of reliable crash data in many developing countries, appropriate road maintenance measures are facing great troubles. In light of that, several proactive methods in defining road's safety level such as Road Assessment Program (RAP) have emerged. This research aim to compare two proactive methods that have been tested in Malaysian roads; road assessment program and road environment risk index which was developed based on composite index theory in defining road's safety level. Composite road environment risk index was combining several crucial environment indicators, assigning weight and aggregating the individual index together to form a single value representing the road's safety level. Based on the results, it can be concluded that both road assessment program and composite road environment risk index are contradicted in six different ways such as type of speed used, type of analysis used and their final outcomes. However, with an aim to promote safer roads, these two methods can be used concurrently as the outcomes in both methods seems to fulfil each other's gap very well.
\end{abstract}

\section{Introduction}

In country like Malaysia who is still at its early phase of instilling road safety educations, having new system that is capable to elaborate the most crucial aspect of the road can be seen as a start for a better road traffic system. Apart from that, development of road safety index in Malaysia was also seen as a proactive measure in identifications of problematic road sections that require urgent treatment [1]. Malaysia has experience very high number of crash where most of the road safety evaluation is based on the crash record (reactive measure). Based on this data, lots of programmes have been initiated to help educating Malaysian road users. However those programmes seem to be insufficient in reducing the number of crashes in Malaysian roads and transforming the people's behaviour and perceptions towards road safety [2]. In an attempt to overcome this issue, a proactive

\footnotetext{
* Corresponding author: intan@ump.edu.my
} 
method of composite road safety index targeting at the environment factor of the road was developed to proactively determine risky road sections before crashes was initiated.

\section{Concept of composite road safety index for road safety evaluation}

According to [3], development of road safety index may not possibly show the whole road safety picture in a country but at least this index should be able to show most of the picture. Crash were suspected to be contributed by various factors so examining a single factor at one time is seems to be insufficient. A single system that can capture all those factors inwhole and can be further used to elaborate the process leading to crash as well as suggesting a countermeasure is believed to be the best solutions. In compliance to that, European Transport Safety Council (ETSC) has come out with an idea of road safety performance indicator where the outcome is a single value. According to [4], safety performance index (SPI) was defined as a measure to reflect the operational conditions of the road traffic system, which influence the system's safety performance. The main characteristic of the safety performance index is its ability in giving out a more complete picture of the road safety status and can also point the emergence of developing problems at an early stage, before these problems show up in the form of accidents [5]. In short, safety performance index has been recognized to have below credibility:

- To reflect the current safety conditions of a road traffic system (i.e. they are considered not necessarily in the context of a specific safety measure, but in the context of specific safety problems or safety gaps)

- To measure the influence of various safety interventions

- To compare different road traffic systems (e.g. countries, regions, etc).

Realizing the needs to combine as much information as possible from current road conditions in mitigating correct crash factors, a concept of composite index was introduced. Here, each indicator developed from the targeted road aspect was given specific weight and were later combined to produce single value which represented the road safety status for the selected area. As indicated by [3], the philosophy of combining performance outcomes into one single quantitative value, so called "composite index", is not a new one. Although the development of composite index is seen as a challenging matter to road safety researcher [6], this index is desperately needed as an easy and understandable tools for policy makers as well as the public to measure the road safety status [3]. In line with that, many composite indices have been developed internationally and used across fields to indicate a progress or achievement between comparable entities such as countries.

\subsection{Road assessment program (RAP) method}

International road assessment program or better known as iRAP is a continuation from similar successful road assessment programmed carried out in United States of America (usRAP), European Countries (EuroRAP) and Australia (AusRAP) to name a few. Main outcomes generated from this road assessment programmed were the risk mapping and the performance tracking protocols where both of the protocols were aims at producing safer road networks focusing at developing countries. According to iRAP report produced in year 2011, risk mapping is a map produced from sets of crash data used to show the sections of road where the risk level was high. Performance tracking on the other hand is a protocol used to identify consistently high risk roads and the most improved roads so that benchmarking between the high risk road and the improved roads can be done. 
Within the iRAP procedures, detailed visual inspections of road's infrastructure elements that were known to have impact on the likelihood of a crash were carried out using drive-through and video based inspection. The results from the inspections and video recordings were used to calculate star rating for every $100 \mathrm{~m}$ road sections using Road Protection Score (RPS) method. RPS is a unit-less measurement represented in either 5-star for safest infrastructure conditions and 1-star to the riskiest infrastructure conditions.

RPS are calculated by focusing on three different road infrastructure factors chosen as the most critical road infrastructure factors; the median, the side area and the junction areas. It is important to note that the Star Rating represents the safety risk faced by an individual road user if they (or the traffic around them) are travelling within the speed limit. Traffic flow and estimation of actual speeds are not included in the calculation.

Fig. 1 shows a car occupant star rating along most Malaysian Expressway and Federal roads and specifically along Federal Road 3 start from Kuantan to Kuala Rompin, Pahang. Calculation of star rating for this stretch of road shows that more than $50 \%$ of roads are rated as having a 2 star (red colour) infrastructures conditions.

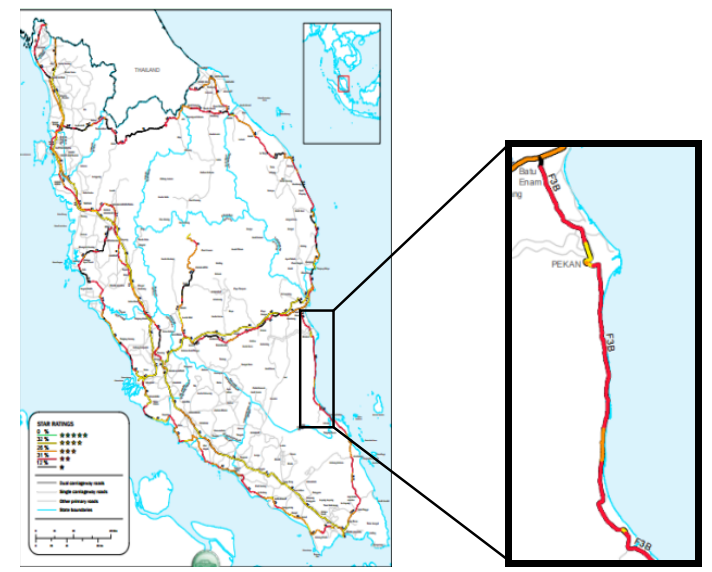

Fig. 1. Car Occupant's Star Rating for Malaysia Roads (iRAP Malaysia Results, 2009)

Major upgrading works have been done in year 2011 to this particular road section where part of road from Batu Enam to Pekan for approximately about $45 \mathrm{~km}$ length has been upgraded to dual carriageway road with concrete median to separate opposing traffic flow as shown in Fig. 2. Nevertheless, based on crash data Royal Malaysia Police Force in year 2012, numbers of crashes in this road are still soaring up to 18 crashes $/ 500 \mathrm{~m}$ road length.

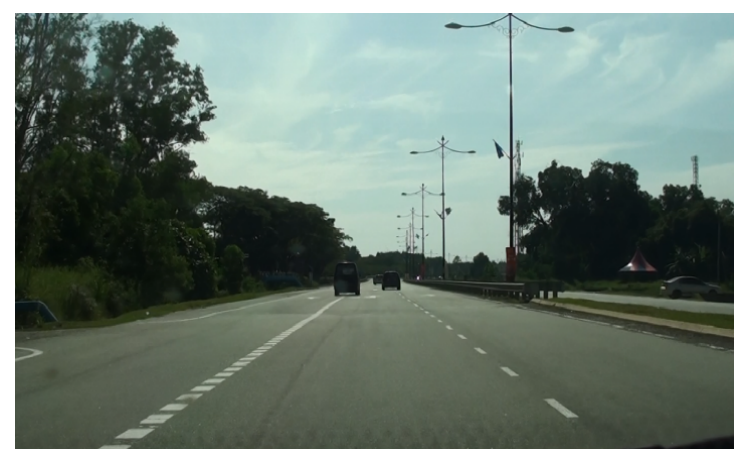

Fig. 2. Current Condition of Road between Batu Enam and Pekan 


\section{Road environment safety evaluation based on composite road safety index}

A stretch of road within Federal Road 3 has been chosen as the research area where the principle of composite road safety index was tested. This road starts at Skudai Town and ends at Rantau Panjang, Kelantan with $739 \mathrm{~km}$ in total length. The stretch of road adopted as study area is between KM 183 and KM 318 making a total of $135 \mathrm{~km}$ length road. Road environment factor was chosen as the main research theme since the complexity of road environment has been proven to be highly related in producing high risk to drivers [7] especially in developing countries like Malaysia who has a very unique road environment factors that need to be further explored [8]. Fourteen indicators comprised of 12 numerical indicators and 2 categorical indicators as shown in Table 1 below were used to represent the local road environment conditions of this area.

Table 1. Selected road environment indicators

\begin{tabular}{|c|}
\hline Road Environment Indicators \\
\hline \hline Number of Motorcycles/section \\
Number of Pedestrian /section \\
Percentage of Poor Roadway Condition \\
Number of Lanes/section \\
Percentage of Unpaved Shoulder/section \\
Percentage of Poor Road Delineation/section \\
Percentage of Roadside Development/section \\
Number of non-Signalized Access/section \\
Number of Signalized Intersection/section \\
Percentage of Road Without Median \\
Lane Changing Opportunity \\
Non-Traversable Object at Roadside \\
Number of Heavy Vehicles/section \\
Actual Driving Speed/section \\
\hline
\end{tabular}

The criteria in developing the road environment risk indicators were done by adapting the criteria proposed for the development of road safety performance indicators prepared by SafetyNet through its report entitled 'State of the Art Report on Road Safety Performance Indicators, 2005 and thesis written by [3]. The criteria set - up for constructing the road environment risk indicators are as listed below.

- Indicators must be designed to be highly accurate in explaining the road environment dimension.

- Indicators must have clear objectives, clear measurement methods and expectations.

- Each indicator is possible to thoroughly explain the outcomes expected to be derived from the indicators.

- Each indicator must be quantifiable in a sense that possible and reasonable score could be obtained.

- The indicators should express an ordinal relation with road risk (slight changes in score will gives very clear changes on road risk level).

Indicators can be measured in terms of a percentage, a rate, an exact values or even a level of qualitative statements such as very good, good and poor [3]. In comparions with the development of RAP, the selection of each indicator/attribute is somewhat different. While RAP's attributes are focusing on developing a scale showing how well road protects their user from death or serious injuries once the accident occurs, indicators in composite road safety index is measuring the risk generated from the selected indicators where the indicators must reflect their level of risk towards drivers 
After conducting several preliminary analyses to test the suitability of each environment indicator to be included in the development of the composite road environment safety index, four indicators have been excluded from the dataset. The balance of 10 indicators have been combined together and produced a Kaiser-Meyer-Olkin (KMO) value of 0.760 and Bartlett's significance value of 0.0001 indicating that this combination has an ability to produce good road environment risk index. Principal component analysis (PCA) has been chosen as the extraction method in the development of the composite index. Results from several iterations using PCA and Varimax with Kaiser normalization as extraction and rotation method respectively, shows that those indicators could be further classified into three different groups representing three different environment characteristics. Fig. 3, 4 and 5 show a composite index value of each section within the study area according to its characteristic.

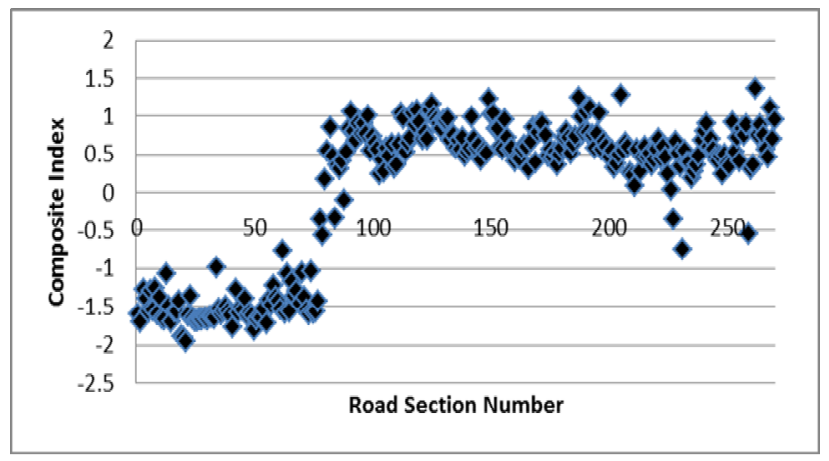

Fig. 3. Road Section's Composite Index based on Infrastructure Environment Risk Factor: Federal Road 3

Fig. 3 clearly shows the trend of risk generated from road infrastructure environment of this study area. This study area is a double carriageway lane with concrete median for the first $45 \mathrm{~km}$ of the road and the rest of the road is a multilane road. The difference in its infrastructure environment was clearly illustrated in this figure where areas equipped with raised median to separate the opposing traffic have significantly lower risk compared to areas where no raised median is built.

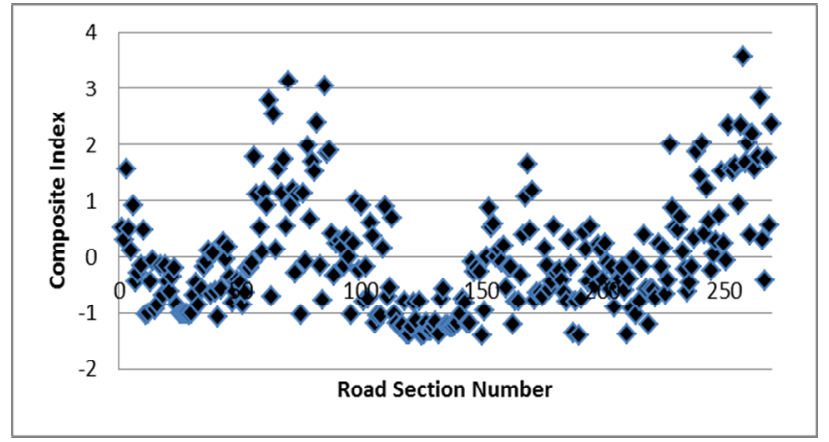

Fig. 4. Road Section's Composite Index based on Roadside Environmnet Risk Factor: Federal Road 3

Fig. 4 shows the composite index value of the road sections based on roadside environment risk factor. A clear fluctuating trend can be observed where the risks generated from roadside environment are quite high in certain locations and low in certain locations. This study area is encompassing two major towns i.e. Pekan and Kuala Rompin where the 
roadside activities in these two towns are very high. So it could be early concluded that the two major peaks (highest risk) as depicted in above figure are actually representing these two towns.

Fig. 5 shows the composite index values calculated from operational environment risk factor of this area. The composite index trend shows that the composite values are extremely high in several sections indicating that the risks of operational environment in those particular sections are also very high. It is also observed that numbers of sections with low composites values are higher compared to sections with high composite index values.

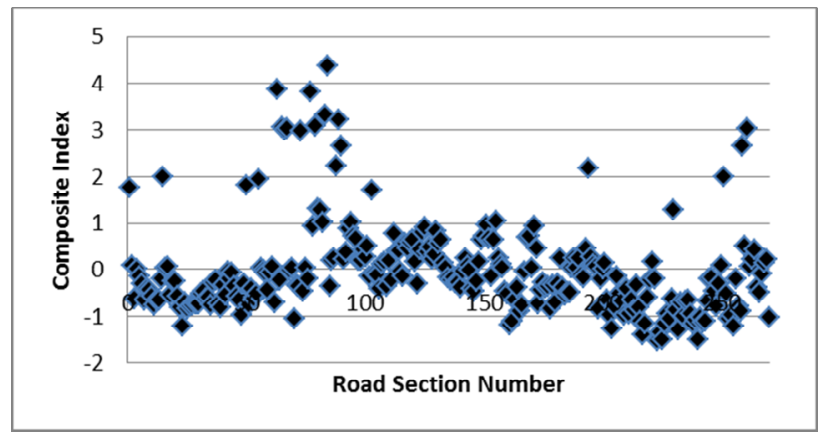

Fig. 5. Road Section's Composite Index based on Operational Environmnet Risk Factor: Federal Road 3

Based on these figures, the composite index values of the continuous road sections would generally indicates the trend of road environment risk along the study area where in general, comparison between high risk sections with low risk sections can be directly detected.

\section{Composite road safety index vs. road assessment program}

Based on the brief introductions of both methods above, it can be clearly observed that both composite road environment risk index produced from this research and the concept of star rating produced by iRAP team shared the same aim; providing safer road to the road users. Table 2 shows the comparisons between composite road safety index and iRAP's procedures in producing safer roads.

Final outcomes of road environment risk index is a single value called composite index for each road sections which were used to rank each section risk level so that the riskiest sections could be correctly identified. iRAP's final outcomes are values calculated from 3 main road infrastructure aspects translated into 1-5 star rating relates to the risk faced by individual member of each road user group (motorcyclist, car occupant etc).

Based on the Table 2, it was concluded that there were six substantial differences in the procedures of safety status evaluations between the composite road environment risk index and iRAP's procedure. The differences were mainly on the main frameworks which involved the main parts of the procedures. However, one of the important advantages that iRAP procedures had was the ability of the star rating in fulfilling the basic needs of a road rating theory; the calculation of risk based on different types of road users i.e. the car occupant, motorcyclist, bicyclist and pedestrians.

It is generally acknowledged that different type of road users experienced different source of risk while travelling on the road. Risks faced by car drivers and risk faced by motorcyclist for example is totally different. While car drivers is safely prohibited in an hard shell of steel, motorcyclist on the other hand have to face risk coming from all angle 
thus have a very limited opportunity to protect themselves from being injured or fatal [9$12]$.

Table 2. Comparisons of Final Outcomes from Composite Road Safety Index and iRAP's Star Rating

\begin{tabular}{|c|c|}
\hline Composite Road Safety Index & $\begin{array}{c}\text { Star Rating : International Road Assessment } \\
\text { Programme }\end{array}$ \\
\hline Measuring the risk level of the road sections. & $\begin{array}{l}\text { Measuring the safety performance of a road } \\
\text { network }\end{array}$ \\
\hline $\begin{array}{l}\text { Targeting on specific road environment } \\
\text { attributes that known to instantly generate } \\
\text { risks towards car drivers and triggering } \\
\text { crash. }\end{array}$ & $\begin{array}{l}\text { Covering the aspects of road infrastructures that } \\
\text { known to influence likelihood of crash and } \\
\text { severity }\end{array}$ \\
\hline $\begin{array}{l}\text { The road environment indicators were } \\
\text { weighted and individual index of each } \\
\text { indicator was calculated based on statistical } \\
\text { method. }\end{array}$ & $\begin{array}{l}\text { The road attributes were scored based on } \\
\text { judgments of the selected road inspectors from } \\
\text { video recordings of the road areas. }\end{array}$ \\
\hline $\begin{array}{l}\text { The weight of each indicator was calculated } \\
\text { based on the exclusive behavior / } \\
\text { characteristics of the indicators itself on each } \\
\text { road network. }\end{array}$ & $\begin{array}{l}\text { The weight of each road infrastructure aspects } \\
\text { was pre-determined based on the level of risk } \\
\text { produced by each road infrastructure aspects }\end{array}$ \\
\hline $\begin{array}{l}\text { Actual speed was used throughout the } \\
\text { composite index calculation so that the } \\
\text { actual risk experienced by the road users was } \\
\text { presented. }\end{array}$ & $\begin{array}{l}\text { Posted speed limit was used in determination of } \\
\text { the risk resulting to final outcomes was only } \\
\text { valid if only the road users is travelling within the } \\
\text { speed limit. }\end{array}$ \\
\hline $\begin{array}{l}\text { Final outcomes were single values called } \\
\text { composite index for each road sections } \\
\text { which were used to rank each section risk } \\
\text { level so that the riskiest sections could be } \\
\text { correctly identified. }\end{array}$ & $\begin{array}{l}\text { Final outcomes are values of calculated from } 3 \\
\text { main road infrastructure aspects translated into } \\
1-5 \text { star rating relates to the risk faced by } \\
\text { individual member of each road user group } \\
\text { (motorcyclist, car occupant etc). }\end{array}$ \\
\hline
\end{tabular}

Since this is the first research to test the applicability of composite index in evaluating the road section's risks based on prevailing road environments condition in developing countries, only one type of road users were taken into considerations. Considering huge numbers of cars used by most road users, car drivers was taken as the main issues despite motorcycles who is also one of the most commonly used vehicles in developing countries especially in South East Asia countries. But, since motorcycles are quite uncommon in other developing countries like Chile, Costa Rica and most of South African countries [13], car drivers was mostly suitable to use as preliminary subject of this research. This would allow for wider usage of the research outcomes.

Other than that, final outcomes derived from both methods were also different. While composite road environment risk index presented the risk level of each road sections in terms of the composite index value, iRAP procedures was presenting the safest road infrastructure design through star rating received by each road networks with 5 -star represents the safest road infrastructure design for the prevailing speed limits. This has come to a conclusions that 5-star given to the road infrastructure built in federal road with a speed limit of $90 \mathrm{~km} / \mathrm{h}$ is incomparable with 5-star given to the road infrastructures designed for expressway having a speed limit of $110 \mathrm{~km} / \mathrm{h}$. Taking road barrier for example, the safest design of road barriers for motorcyclist traveling on federal road with speed limit of $90 \mathrm{~km} / \mathrm{h}$ would not necessarily be given 5 -star if the same design was applied within an expressway with speed limit of $110 \mathrm{~km} / \mathrm{h}$. Better barrier's design must be introduced to accommodate the needs to have the safest barriers for motorcycles at prevailing speed limit of $110 \mathrm{~km} / \mathrm{h}$. This is the challenges that must be faced by the road improvements departments since they have to design range of road infrastructures aspects for every type of road having different speed limits. 
Crashes always occurs in an event of speeding [14], so by only studying the safest road infrastructure for road users who are travelling within the speed limit is insufficient to represent the real road situations especially if the main aim of the assessment program is to reduce the number of crashes and providing safer roads in general. Moreover, as indicated by [15], most road users doesn't always aware of the posted speed limits during their driving period whereas the environment of the roads is always being used as indicators in defining their prevailing speeds. So, it was clear that designing a system that highly depended on the speed limits was insufficient in evaluating the exact situations of the roads.

\section{Conclusion}

In overcoming this issue and in an attempt to ensure that the developed composite index is presenting actual conditions of the roads, the theory of naturalistic driving method was applied in this study. Naturalistic driving method was defined as data collection method where the research subject (car drivers in this case) would drive its own car, under its normal conditions, without any descriptions or interventions from the data collection procedures and the drivers was allows to drives just like they normally do [16]. The outcomes generated using this method was very helpful especially in defining the relationship between road users, road, traffic and the environment under driver's normal conditions. Hence, this efforts were seems to be appropriate in filling in the missing part in iRAP method.

\section{References}

[1] N. Daud, K. Ibrahim, K. Sopian, Hierarchical bayesian approach for ranking of accident blackspots with reference to cost of accidents, 2nd WSEAS Int. Conf. on Computer Engineering and Applications (CEA'08) Acapulco, Mexico, (2008)

[2] S.H. Musthar, M. Muda, B.M. Adji, M.R. Karim, Audience involvement in Malaysian road safety campaigns among young adults, Proceeding of the Eastern Asia Society for Transportation Studies, 9, (2013)

[3] A.H. Ghazwan, Road Safety Development Index, Dissertation Number: 1100, ISBN: 978-91-85715-04-6, Linkoping University, (2007)

[4] European Transport Research Council, Transport Safety Performance Indicators, ISBN: 90-76024-11-1 2, (2001)

[5] A.S. Hakkert, V. Gitelman, Road Safety Performance Indicators: Manual, Deliverable D3.8 of the EU FP6 Project SafetyNet, (2007)

[6] E. Hermans, F. Van den Bossche, G. Wets, Combining road safety information in a performance index, Accident Analysis and Prevention, 40, 1337-13 (2008)

[7] C.M. Rudin-brown, J. Edquist, M.G. Lenné, Effects of driving experience and sensation-seeking on drivers' adaptation to road environment complexity. Safety Science, 62,121-129 (2014)

[8] L. Rogers, H. Hashim, Star Rating Road Improvements: 2009 Malaysia Black Spot Programme, International Road Assessment Programme (iRAP), Report Number 504.10, (2011)

[9] H. Hussain, Development of Capacity and Level of Service for Uninterrupted Exclusive Motorcycles Lanes in Malaysia, PhD Thesis, Universiti Putra Malaysia, (2006)

[10]L.B. Meuleners, A.H. Lee, C. Haworth, Road environment, crash type and hospitalisation of bicyclists and motorcyclists presented to Emergency Departments in Western Australia, Accident Analysis and Prevention, 39, 1222-1235 (2007) 
[11]S.M. Rifaat, R. Tay, A. De Barros, Severity of motorcycle crashes in Calgary, Accident Analysis and Prevention, 49, 44-49 (2012)

[12]M.G. Masuri, K.A.M. Isa, M.P.M. Tahir, Children, youth and road environment: Road traffic accident, Procedia - Social and Behavioral Sciences, 38, 213-218 (2012)

[13]iRAP and EuroRAP, Crash Rate-Star Rating Comparisons, Review of Available Evidence, Working Paper Number 504.2, (2011)

[14]B. Fildes, S. Lee, The Speed Review: Road Environment, Behaviors, Speed Limit, Enforcements and Crashes, Monash University Accident Research Center, A report prepared for Road Safety Bureau, Roads and Traffic Authority of New South Wales and Federal Office of Road Safety Department of Transport and Communications, (1993)

[15]S. Daniels, J. Vanrie, A. Dreesen, T. Brijs, Additional road markings as an indication of speed limits: results of a field experiment and a driving simulator study, Accident Analysis and Prevention, 42, 953-960 (2010)

[16] SWOV, Fact Sheet on Naturalistic Driving: Observing Everyday Driving Behaviour, Leidschendam,1-53 (2010) 